\title{
EDITORIAL
}

\section{The misuse of science}

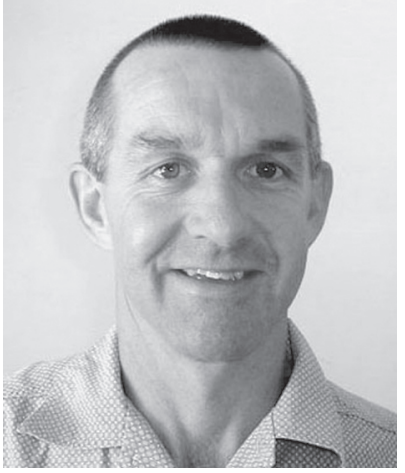

Commercial companies in the health and fitness industry often misuse 'science' in an attempt to gain credibility so that they can sell more products and make more money. A product supported by 'science' creates the impression that it is a worthy product. As laypeople are generally poorly educated on the role of science in health and fitness, they are often influenced by the many adverts that take advantage of this. For example, some companies market their products using terms such as 'doctors agree ..., experts have shown...', or have adverts with pictures of learned-looking people wearing white lab coats next to their product. Other marketing material proudly claims that the product '...has been tested at a South African university'. While this statement may be true it lacks any sense with regard to supporting the efficacy of the product. One can do an experiment on the ergogenic effects of a piece of coal and honestly claim that it has been 'tested', even if it has absolutely no positive ergogenic effect. Proving efficacy, validity, repeatability and potential side-effects of a product is another matter entirely. These are characteristics that have to be identified before legitimate claims can be made, and it may take several years of experimentation to accumulate the knowledge.

Strategies for misusing 'science', such as those outlined above, are successful in South Africa largely because of the stance of the Advertising Standards Authority (ASA) which seems to prioritise legal matters over scientific facts and is too easily influenced by pseudo-science. ${ }^{1}$ This has made 'South Africa a great place for pedlars of snake-oils, slimming aids and unproved "therapies"'.

The first step in changing this paradigm is to educate the public on the role of science in developing knowledge. The scientific process begins with research that attempts to answer a question. In sports medicine the question is often identified by the coach, trainer or players. Sometimes physiotherapists formulate a question and sometimes a doctor identifies a relevant question for which there is no immediate answer. The point is that it does not matter where the question originates. A good research study is one that has a clearly identified question that is relevant. Ernest Rutherford, a pioneering nuclear physicist who won the Nobel Prize for his work has been quoted as saying 'A theory that you can't explain to a bartender is probably no damn good' (quoted in Francis Collins, The Language of God, 2006:60). This same logic can be applied to simplifying questions around which research studies are designed.

A clear, relevant question initiates a process of designing a study that attempts to answer the question. Factors such as type of subjects, adequate control, and sample size to make the data interpretable and representative have to be considered. Well-designed studies that consider these points have a high 'believability' factor and contribute towards providing an answer to the question around which the study was designed. The process does not end there. After implementing the study plan the researchers still have to prepare the manuscript and subject it to peer review in an attempt to get it published. This is not an easy task. Most of the top international journals have rejection rates of around $70 \%$. In an analysis of research papers published in 6 leading basic science journals (approximately 25000 papers), only $2 \%$ of the studies contained some information that had the potential to make a significant contribution to clinical application. ${ }^{2}$ The rate of transfer of knowledge from research into practice is low. This can be illustrated in the acquisition of the practical knowledge on carbohydrate ingestion during exercise. In the last 30 years 1103 studies have investigated carbohydrate ingestion and exercise (accessed from PubMed using the keywords 'carbohydrate', 'ingestion' and 'exercise'). The collective knowledge from all these studies can be reduced to about 10 practical points. There are many other examples of routine practices in sports medicine which have evolved from systematic research.

The following are thanked for reviewing manuscripts submitted to the SAJSM during 2006. All these reviewers have made a significant contribution to the peer-review process which is the core to developing knowledge.

$\begin{array}{ll}\text { Aginsky K } & \text { McKune A } \\ \text { De Beer J } & \text { Meurer B } \\ \text { De Milander L } & \text { Micklesfield L } \\ \text { De Villiers R } & \text { Potter P } \\ \text { Dugas J } & \text { Raine R } \\ \text { Durandt J } & \text { Reid S } \\ \text { Gay J } & \text { Saunders C } \\ \text { Gray A } & \text { Smith C } \\ \text { Havemann L } & \text { Smith J } \\ \text { Johnston R } & \text { Stretch R } \\ \text { Keet J } & \text { Swart J } \\ \text { Kohler R } & \text { Viljoen W } \\ \text { Lambert V } & \text { Wright Z } \\ \text { Manjra S } & \end{array}$

This is the first of 4 issues of the SAJSM for 2007. I trust that you will enjoy reading it and that the papers published in this issue will contribute in some way to the promotion of sports medicine in an evidence-based way!

\section{Mike Lambert}

Editor-in-Chief

1. Welz M, ed. Fat chancers. Noseweek 2007; 89: 18-21.

2. Bishop DB, Burnett A, Farrow D, Gabbett, T, Newton, R. Sport science roundtable: Does sports-science research influence practice? International Journal of Physiology and Performance 2006; 1(2): 161-8. 